\title{
Cobalamin-Associated Superoxide Scavenging in Neuronal Cells Is a Potential Mechanism for Vitamin $B_{12}$-Deprivation Optic Neuropathy
}

\author{
Wesley Chan, ${ }^{*}$ Mohammadali Almasieh, ${ }^{* \dagger}$ Maria-Magdalena Catrinescu, ${ }^{* \dagger}$ and Leonard A. Levin ${ }^{\star \dagger \ddagger \xi}$
}

From the Maisonneuve-Rosemont Hospital Research Center and Department of Ophthalmology, * University of Montreal, Montreal, Quebec, Canada; the Departments of Ophthalmology ${ }^{\dagger}$ and Neurology and Neurosurgery, ${ }^{\ddagger}$ McGill University, Montreal, Quebec, Canada; and the Department of Ophthalmology and Visual Sciences, ${ }^{\S}$ University of Wisconsin School of Medicine and Public Health, Madison, Wisconsin

\author{
Accepted for publication \\ August 28, 2017. \\ Address correspondence to \\ Leonard A. Levin, M.D., Ph.D. \\ Department of Ophthalmology, \\ McGill University, 5252 Blvd \\ de Maisonneuve W, Montreal, \\ QC, Canada H4A 3S5. E-mail: \\ leonard.levin@mcgill.ca.
}

\begin{abstract}
Chronic deficiency of vitamin $B_{12}$ is the only nutritional deficiency definitively proved to cause optic neuropathy and loss of vision. The mechanism by which this occurs is unknown. Optic neuropathies are associated with death of retinal ganglion cells (RGCs), neurons that project their axons along the optic nerve to the brain. Injury to RGC axons causes a burst of intracellular superoxide, which then signals RGC apoptosis. Vitamin $B_{12}$ (cobalamin) was recently shown to be a superoxide scavenger, with a rate constant similar to superoxide dismutase. Given that vitamin $B_{12}$ deficiency causes an optic neuropathy through unknown mechanisms and that it is a potent superoxide scavenger, we tested whether cobalamin, a vitamin $\mathrm{B}_{12}$ vitamer, would be neuroprotective in vitro and in vivo. We found that cobalamin scavenged superoxide in neuronal cells in vitro treated with the reduction-oxidation cycling agent menadione. In vivo confocal scanning laser ophthalmoscopy demonstrated that optic nerve transection in Long-Evans rats increased superoxide levels in RGCs. The RGC superoxide burst was significantly reduced by intravitreal cobalamin and resulted in increased RGC survival. These data demonstrate that cobalamin may function as an endogenous neuroprotectant for RGCs through a superoxide-associated mechanism. (Am J Pathol 2018, 188: 160-172; https://doi.org/10.1016/j.ajpath.2017.08.032)
\end{abstract}

The optic nerve relays visual stimuli from the retina to the brain and is composed of retinal ganglion cell (RGC) axons. When the optic nerve is damaged because of injuries or disease (eg, optic neuropathies), the RGC soma activates a programed cell death pathway and undergoes apoptosis, resulting in irreversible visual loss. A common feature of optic neuropathies is axonal injury, the most prevalent being glaucoma, the leading cause of blindness worldwide. ${ }^{1}$ In the United States alone, an estimated 2.2 million individuals are affected by glaucoma, ${ }^{2,3}$ the prevalence of which is expected to increase as the population ages.

Optic neuropathies arise from multiple causes, including glaucoma, ${ }^{4}$ ischemia, ${ }^{5}$ tumors, ${ }^{6}$ infection, ${ }^{7}$ and trauma. ${ }^{8}$ Although often overlooked, deficiencies of critical vitamins and nutrients can also lead to vision problems. ${ }^{9-11}$ Vitamin $B_{12}$ (cobalamin) deficiency, in particular, is known to lead to bilateral optic neuropathy, characterized by cecocentral scotomas and the slow development of optic atrophy, $^{12,13}$ in addition to more common hematological, neurological, and neuropsychological manifestations. ${ }^{14}$

Cobalamin is an essential micronutrient acquired through the diet in animal products, such as meat and eggs. ${ }^{9,15,16}$ Digestion of food by stomach pepsin and hydrochloric acid releases cobalamin and allows its binding to intrinsic factor. ${ }^{17}$ The intrinsic factor-bound cobalamin travels through the small

\footnotetext{
Supported by Canadian Institutes for Health Research; the Canadian Foundation for Innovation; the Canadian Research Chairs program; Fonds de Recherche en Ophtalmologie de l'Université de Montréal; NIH grants R21 EY017970, R21 EY025074, and P30 EY016665; the Retina Research Foundation; and Research to Prevent Blindness. L.A.L. is the Canada Research Chair in Translational Visual Science.

W.C. and M.-M.C. contributed equally to this work.

Disclosures: L.A.L. is a consultant to Aerie, Inotek, Quark, Regenera, and Teva.
} 


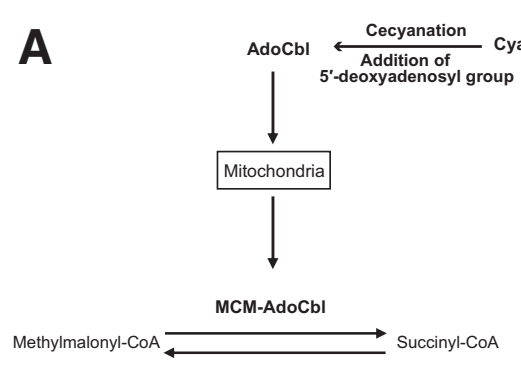

B

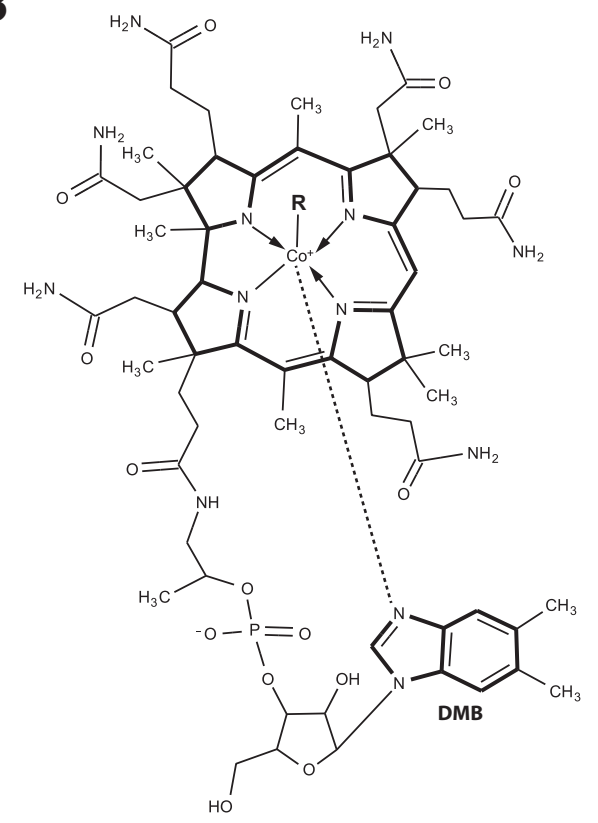
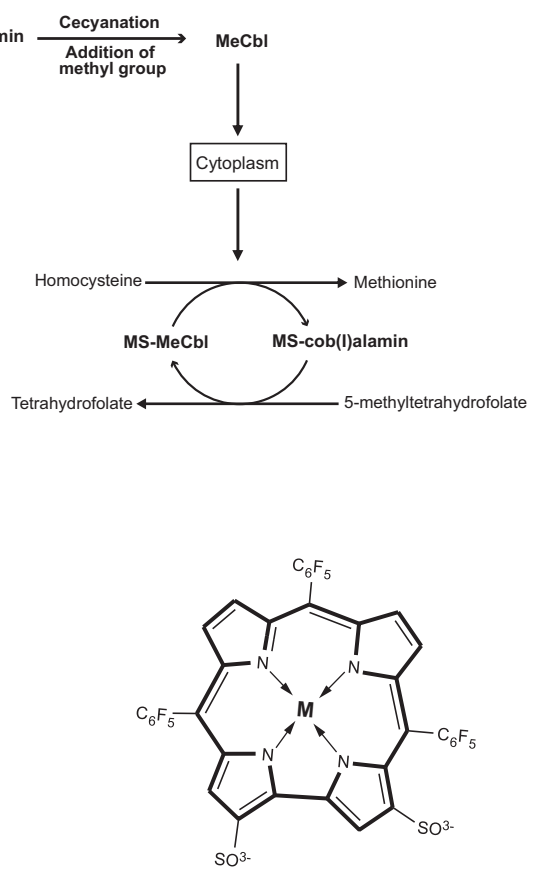

Figure 1 Cobalamin metabolism, function, and structure. A: Cyanocobalamin (CNCbl) undergoes a reductive decyanation in the cellular cytoplasm before conversion to methylcobalamin $(\mathrm{MeCbl})$ and 5'-deoxyadenosylcobalamin (AdoCbl). Cobalamin derivatives methylcobalamin and $5^{\prime}$-deoxyadenosylcobalamin are cofactors involved in methionine synthesis and propionate metabolism, respectively. AdoCbl is required by methylmalonyl CoA mutase (MCM) for the conversion of methylmalonyl-CoA to succinyl-CoA. MeCbl is the cofactor for methionine synthase (MS) and loses its methyl group to become cob(I)alamin in the production of methionine and gains the methyl group again from 5-methyltetrahydrofolate in the production of tetrahydrofolate. B: Chemical structures of cobalamin (left panel) and metallocorrole (right panel). Cobalamin scavenges superoxide. ${ }^{30}$ DMB, 5,6-dimethylbenzimidazole. intestine and is absorbed by the distal ileum on attachment to cubilin, the receptor for intrinsic factor, located on ileal mucosal cells. $^{18,19}$ Once in mucosal cells, cobalamin is freed from intrinsic factor by the action of lysosomal enzymes, ${ }^{17}$ binds to transcobalamin II, and is then secreted into the bloodstream to be taken up by cells or stored in the liver. ${ }^{20}$ Cyanocobalamin $(\mathrm{CNCbl})$, the form of cobalamin most commonly used in supplements, undergoes a reductive decyanation process in the cellular cytoplasm before conversion to methylcobalamin and $5^{\prime}$-deoxyadenosylcobalamin. ${ }^{21}$ Methylcobalamin acts as a cofactor for methionine synthase in the cytoplasm, whereas $5^{\prime}$ deoxyadenosylcobalamin is a cofactor for methylmalonyl CoA mutase in mitochondria. These enzymes are critical for amino acid synthesis and the citric acid cycle ${ }^{22,23}$ (Figure 1A).

Several proteins help target methylcobalamin and 5 -deoxyadenosylcobalamin into the relevant cellular compartments and enable them to function as a cofactor. ${ }^{21}$ Inherited defects of these proteins leads to functional defects in methionine synthase (homocystinuria) ${ }^{24,25}$ or methylmalonyl CoA mutase (methylmalonic acidemia). Hereditary disorders of cobalamin metabolism have ocular manifestations, such as photoreceptor and ganglion cell loss, ${ }^{26}$ optic nerve atrophy, and macular degeneration. ${ }^{27,28}$
Recent reports indicate that cobalamin can act as an intracellular superoxide scavenger ${ }^{29}$ and is able to protect cultured cells by neutralizing superoxide. ${ }^{30,31}$ These findings suggest that cobalamin may play an additional role beyond its known cofactor functions (Figure 1A). Superoxide is produced as a byproduct of electron transport chain leakage reacting with molecular oxygen, ${ }^{32}$ and normally is scavenged by superoxide dismutase (SOD), ${ }^{33}$ thereby protecting mitochondria from constant oxidative damage. Superoxide also has another role in the nervous system, acting as a signal for apoptosis in injured neurons. ${ }^{34-36}$ After axotomy, superoxide signaling of apoptosis can be inhibited through exogenous delivery of pegylated (PEG) $\mathrm{SOD},{ }^{36,37}$ resulting in protection of injured neurons.

The difficulties associated with therapeutic delivery of exogenous SOD prompted the development of small molecules that scavenge superoxide. We recently showed that metallocorroles that scavenge superoxide ${ }^{38}$ can prevent neuronal cell death. ${ }^{39}$ Metallocorroles are small tetrapyrrolic macrocycles that contain a metallic ion in the porphyrin-like inner core. ${ }^{39,40}$ Cobalamin and metallocorroles (Figure 1B) both have a corrin ring as their core chemical structure. The ability of these molecules to scavenge superoxide is likely related to this core corrin ring structure. ${ }^{41,42}$ 


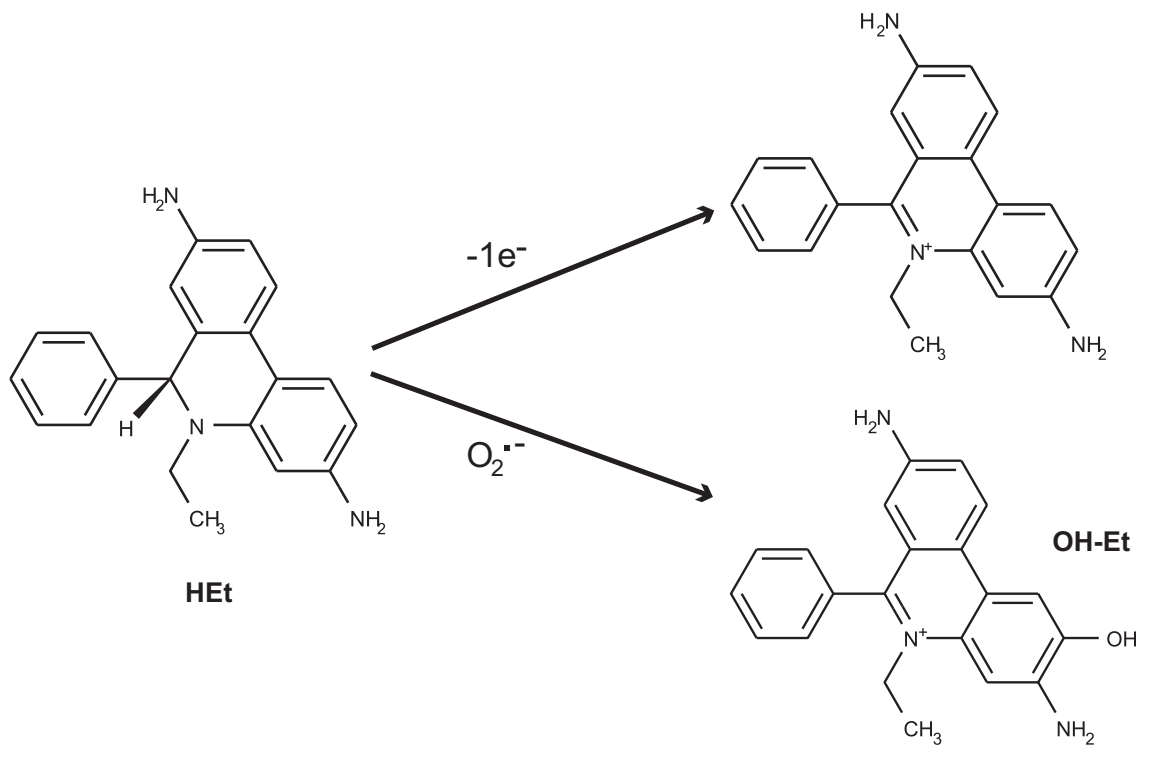

Figure 2 Cobalamin scavenges superoxide in a cell-free system. Chemical structure of hydroethidine (HEt), ethidium (Et), and 2hydroxyethidium (OH-Et). Et is the fluorescent product of a single electron reaction with $\mathrm{HEt}$, whereas $\mathrm{OH}$-Et is the production of the reaction of HEt with superoxide. There is approximately $40 \%$ fluorescence overlap between $\mathrm{OH}$-Et and Et when excited at $510 \mathrm{~nm}$, but only $10 \%$ overlap when excited at $396 \mathrm{~nm} .{ }^{45}$
There are three possible oxidation states for the cobalt atom in the corrin ring of the cobalamin molecule, based on the binding of $\alpha$-axial (a nitrogen of the 5,6-dimethylbenzimidazole) and $\beta$-axial (R-group) ligands. The +3 state [cob(III)alamin] exists in CNCbl, $5^{\prime}$-deoxyadenosylcobalamin, and methylcobalamin; the +2 state [cob(II)alamin] exists if there is no $\mathrm{R}$ group attached to the cobalt; and, finally, the cobalt atom in cobalamin can exist in the +1 state $[\operatorname{cob}(\mathrm{I})$ alamin] when it has no $\alpha$ and $\beta$ axial ligands. $^{24}$

Given that superoxide is a signal for apoptosis after RGC axotomy, ${ }^{36}$ and that cobalamin shares a core structure with superoxide-scavenging and neuroprotective metallocorroles, we hypothesized that cobalamin is an endogenous SOD mimetic, which, when deficient, would lead to RGC death. The mechanism of RGC death in vitamin $B_{12}$ deficiency would result from elevated levels of physiological superoxide, which would aberrantly signal a pathological cell death pathway meant for axonal injury. To explore this hypothesis, we studied the role of cobalamin as a superoxide scavenger and neuroprotectant in vitro and in vivo.

\section{Materials and Methods}

\section{Animals}

Female Long-Evans rats, weighing 225 to $250 \mathrm{~g}$, were obtained from Charles River (Saint-Constant, QC, Canada). Rats were housed in the Maisonneuve-Rosemont Hospital Research Centre Animal Facility (Montreal, QC, Canada) in a temperaturecontrolled environment with a 12-hour light/dark cycle. Food and water were provided ad libitum. Before any surgical or imaging procedure, animals were anesthetized by i.p. injection of $50 \mathrm{mg} / \mathrm{kg}$ ketamine (Vétoquinol, Lavaltrie, QC, Canada) and 100 $\mathrm{mg} / \mathrm{kg}$ xylazine (Bayer, Toronto, ON, Canada). All animal experiments were performed in accordance with the guidelines of the Maisonneuve-Rosemont Hospital Research Centre Animal Care Committee and the Canadian Council on Animal Care.

\section{Materials}

Dulbecco's modified Eagle's medium and fetal bovine serum were from Wisent Inc. (St. Bruno, QC, Canada). Staurosporine was from Alexis Biochemicals (San Diego, CA). Hydroethidine (dihydroethidium; HEt) was from Fluka BioChemika (Buchs, Switzerland). Penicillin-streptomycin, polyethylene glycol conjugated to superoxide dismutase from bovine erythrocytes (PEGSOD), menadione, xanthine, and xanthine oxidase were from Sigma-Aldrich (St. Louis, MO). Phosphate-buffered saline was from Lonza, Inc. (Walkersville, MD). Salmon sperm DNA, calcein-AM, and propidium iodide were from Invitrogen (Carlsbad, CA). 4-[4-(Didecylamino)styryl]-N-methylpyridinium iodide (4-Di-10-Asp) was from Anaspec (Fremont, CA). Cyanocobalamin was from US Biological (Swampscott, MA).

\section{Cell-Free Assays}

Xanthine $(100 \mu \mathrm{mol} / \mathrm{L})$ was mixed with HEt $(100 \mu \mathrm{mol} / \mathrm{L})$, $1 \mathrm{mg} / \mathrm{mL}$ of salmon sperm DNA, and $100 \mathrm{pmol} / \mathrm{L}$ to 100 $\mu \mathrm{mol} / \mathrm{L}$ of cyanocobalamin. This master mix was incubated in quadruplicate in black 96-well plates (Nunc, Rochester, $\mathrm{NY}$ ), and xanthine oxidase $(5 \mathrm{mU} / \mathrm{mL})$ was added last to initiate superoxide generation. Plates were read in a CytoFluor 4000 (Perseptive Biosystems, Framingham, MA) fluorescent plate reader every 10 minutes for an hour at $360 \pm 40$-nm excitation and $580 \pm 50$-nm emission.

\section{Cell Culture}

A subline of photoreceptor $661 \mathrm{~W}$ cells (formerly known as RGC5 cells) that can be differentiated into a neuronal phenotype ${ }^{43}$ were 
A

Vehicle control
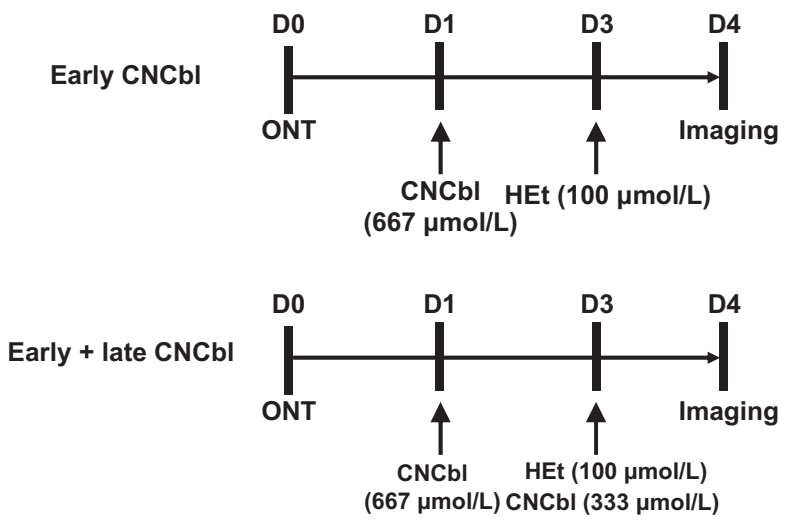

B

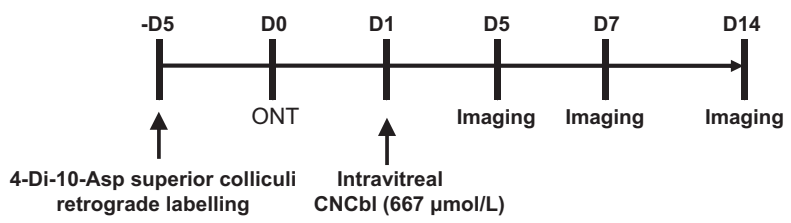

C
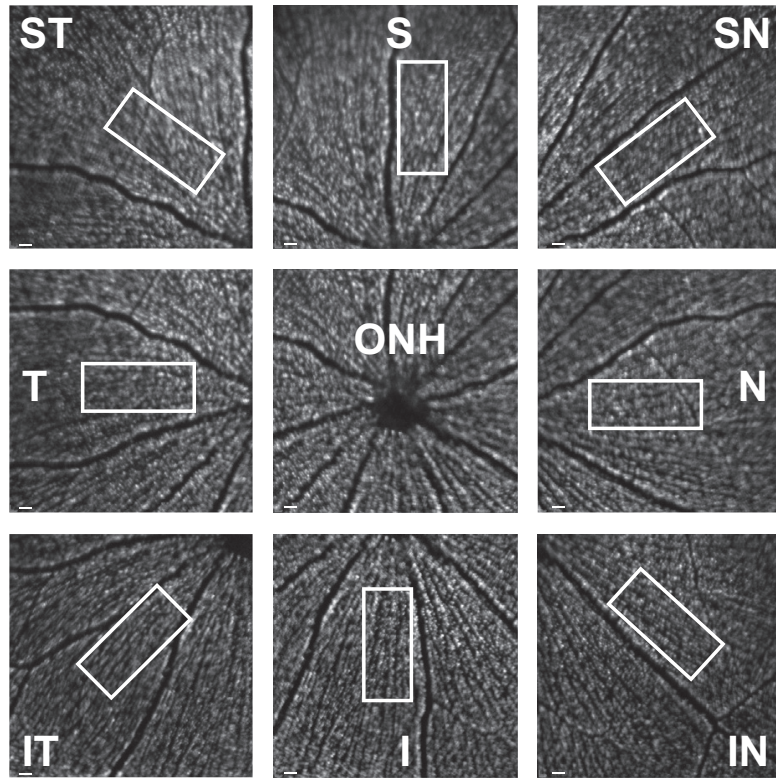
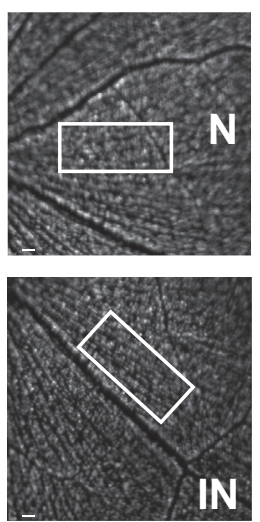

cultured in Dulbecco's modified Eagle's medium containing $1 \mathrm{~g} / \mathrm{L}$ glucose, supplemented with $10 \%$ fetal bovine serum, $100 \mathrm{U} / \mathrm{mL}$ penicillin, and $100 \mu \mathrm{g} / \mathrm{mL}$ streptomycin. Cells were split every 48 to 72 hours when cells were approximately $60 \%$ to $85 \%$ confluent, replated at a $1: 20$ dilution in a $25-\mathrm{cm}^{2}$ flask in $5 \mathrm{~mL}$ of cell culture media, and incubated at $37^{\circ} \mathrm{C}$ in humidified $5 \% \mathrm{CO}_{2}$. For studies using differentiated $661 \mathrm{~W} /$ RGC-5 cells, cells were incubated in media containing 316 $\mathrm{nmol} / \mathrm{L}$ staurosporine for 3 hours to allow cells to differentiate before further treatments. This concentration resulted in minimal cell death when early passages ( 7 to 15 ) were used. For in vitro experiments, cells were seeded into 6-well culture plates (Sarstedt, Nümbrecht, Germany). All experiments were performed in triplicate.

\section{Measurement of Intracellular Superoxide in Vitro}

Differentiated 661W/RGC-5 cells were treated with media containing $15 \mu \mathrm{mol} / \mathrm{L}$ menadione to generate superoxide and treated with scavengers (CNCbl or PEG-SOD) for 24 hours. For the assessment of superoxide levels, HEt was added to the cultures (50 $\mu \mathrm{mol} / \mathrm{L}$ final concentration) for 30 minutes. HEt is the nonfluorescent reduced form of ethidium. ${ }^{44}$ On reacting with superoxide, HEt oxidizes to 2-hydroxyethidium (OH-Et) (Figure 2) and binds to DNA to yield a fluorescent signal (excitation, $396 \mathrm{~nm}$; emission, $579 \mathrm{~nm}$ ) (Figure 2). ${ }^{45}$ Et is the product of the nonspecific oxidation of HEt and is excited at $510 \mathrm{~nm}$ and not at $396 \mathrm{~nm}^{36}$ Thus, OH-Et can be distinguished from Et.

To minimize the effects of light exposure causing photooxidation of HEt, all HEt-related experiments were performed in the dark, including the 30-minute incubation with HEt, rinsing, and microscopy. The excess HEt was rinsed out to avoid photooxidation of free HEt by the microscope light source. Cells could not be fixed because OH-Et fluorescence is transient and disappears with fixation. Similar techniques have recently been published as part of a protocol for measurement of superoxide levels in live cells using $\mathrm{HEt}^{46}$

Figure 3 Outline of the in vivo experimental paradigms and retinal ganglion cell (RGC) counting method. A: Experimental time line to determine superoxide scavenging in vivo. Day 0 (DO) marks the day of optic nerve transection (ONT). Cyanocobalamin (CNCbl) was injected 1 day after transection (D1), 3 days after transection (D3), or both. Hydroethidine (HEt; $100 \mu \mathrm{mol} / \mathrm{L}$ ) was injected intravitreally at D3. Confocal scanning laser ophthalmoscopy imaging was performed 4 days after transection (D4), based on previous studies demonstrating that transected RGCs yield maximal 2-hydroxyethidium staining at that time. ${ }^{36}$ B: Experimental time line for RGC neuroprotection in vivo. RGCs were retrogradely labeled with 4[4-(didecylamino)styryl]-N-methylpyridinium iodide (4-Di-10-Asp) 5 days prior (-D5) to transection (D0). Rats received an intravitreal injection of CNCbl (D1) and were imaged 5, 7, and 14 days after transection (D5, D7, and D14, respectively). C: Example of the method used to count the number of RGCs in a retina labeled with 4-Di-10-Asp. For each time point, eight images were taken in retinal octants adjacent to the optic nerve head $(\mathrm{NH})$, representing superior $(\mathrm{S})$, superior nasal $(\mathrm{SN})$, nasal $(\mathrm{N})$, inferior nasal (IN), inferior (I), inferior temporal (IT), temporal (T), and superior temporal (ST) positions. Boxed areas indicate the fields that were counted relative to the major vessels in each octant to quantitate RGCs at the same locations over time. Scale bars $=400 \mu \mathrm{m}$ (C). 
Table 1 Comparison of Number of Retrograde-Labeled Retinal Ganglion Cells Observed in Vivo with CSLO Compared with Counts of Same Eyes ex Vivo in Whole Mounts of Fixed Retinas, before and after ONT

\begin{tabular}{|c|c|c|c|}
\hline $\begin{array}{l}\text { Method of } \\
\text { counting }\end{array}$ & Before ONT & $\begin{array}{l}7 \text { days after } \\
\text { ONT }+ \text { cobalamin }\end{array}$ & $\begin{array}{l}14 \text { days } \\
\text { after } \\
\text { ONT }+ \\
\text { cobalamin }\end{array}$ \\
\hline CSLO in vivo & $2110 \pm 63$ & $1974 \pm 72$ & $1155 \pm 61$ \\
\hline $\begin{array}{l}\text { Whole mounts } \\
\text { ex vivo }\end{array}$ & $2291 \pm 90$ & $1994 \pm 102$ & $1299 \pm 93$ \\
\hline
\end{tabular}

Data are expressed as means \pm SEM.

CSLO, confocal scanning laser ophthalmoscopy; ONT, optic nerve transection.

Microscope fields were randomly sampled, and all images were obtained with the same exposure settings, using a Zeiss Axio Observer A1 (Zeiss, Toronto, ON, Canada) for quantitative epifluorescence microscopy (excitation, $395 \pm 5.5 \mathrm{~nm}$ and $500 \mathrm{~nm}$ dichroic; emission, $560 \pm 20$ $\mathrm{nm})$. ImageJ software version 1.46c (NIH, Bethesda, MD; http://imagej.nih.gov/ij) was used for image analysis of the $\mathrm{OH}-\mathrm{Et}$ fluorescence signal from cells, as previously described. $^{39}$ Briefly, images were captured with a $20 \times$ objective, opened in ImageJ, and then the following were sequentially applied: Despeckle, Adjust Threshold, and Analyze Particle. The results for each image were exported for data analysis with Excel and JMP version 12 (SAS Institute Inc., Cary, NC).

\section{Fluorescent Live-Dead Assays}

Number 1 glass coverslips (VWR, Radnor, PA) were sterilized by flaming in absolute ethanol before coating with poly-L-lysine (Sigma-Aldrich). Cultured 661W/RGC-5 cells were seeded onto the glass coverslips in 6-well tissue culture plates (Sarstedt). After differentiation, cells were treated with various agents for 24 hours. Cells were then stained with $1 \mu \mathrm{mol} / \mathrm{L}$ calcein-AM and $5 \mu \mathrm{mol} / \mathrm{L}$ propidium iodide in phosphate-buffered saline for 20 minutes at $37^{\circ} \mathrm{C}$ in humidified $5 \% \mathrm{CO}_{2}$. Coverslips were rinsed in phosphatebuffered saline, fixed in $4 \%$ paraformaldehyde for 30 minutes, and then rinsed three times (15 minutes each) with phosphate-buffered saline. Coverslips were mounted onto glass slides using PermaFluor (Thermo Scientific, Waltham, MA) for epifluorescence microphotography with a Zeiss Axio A1 (Zeiss, Göttingen, Germany). Four random microscope fields were captured for each coverslip for analysis. An observer (M.-M.C.) masked to treatment groups manually counted the number of live (calcein-positive) and dead (propidium iodide-positive) cells in each microphotograph.

\section{Optic Nerve Transection}

Optic nerve transection was performed on the right eye of anesthetized rats using a Zeiss operating microscope (Zeiss,
Göttingen, Germany). A lateral canthotomy was performed, and the conjunctiva was incised at the limbus, followed by blunt dissection posteriorly to access the sub-Tenon space. The optic nerve meningeal sheath was incised $2 \mathrm{~mm}$ behind the globe, and the optic nerve was transected using the bevel of a 23-gauge needle. This procedure spared the meningeal vessels, which provide the arterial circulation to the retina, to avoid retinal ischemia. The ocular fundus was examined by indirect ophthalmoscopy immediately after surgery to confirm the integrity of the retinal circulation. Animals with abnormal retinal vessels or retinal edema were not used for further study. At the end of the procedure, the skin was sutured and antibiotic ointment was applied to the site.

\section{Intravitreal Injections}

Intravitreal injections of $\mathrm{HEt}$ and $\mathrm{CNCbl}$ were made immediately posterior to the superotemporal limbus at a 45-degree angle using a 32-gauge needle attached to a $10-\mu \mathrm{L}$ Hamilton syringe (Hamilton, Reno, NV). Figure $3 \mathrm{~A}$ demonstrates the time lines for injections, transections, and imaging in the various experiments.

\section{Retrograde Labeling of Retinal Ganglion Cells}

For the RGC survival experiments, retrograde labeling was performed before optic nerve transection by stereotactic injection of 4-Di-10-Asp into both superior colliculi. ${ }^{36}$ Briefly, anesthetized rats were placed in a stereotactic apparatus, and the cortex surface was exposed by drilling the parietal bone to facilitate dye injection. A total volume of $2.8 \mu \mathrm{L}$ of $100 \mathrm{mmol} / \mathrm{L} \mathrm{4-Di-10-Asp} \mathrm{was} \mathrm{injected} \mathrm{bilat-}$ erally at $6 \mathrm{~mm}$ caudal to bregma and $1.2 \mathrm{~mm}$ lateral to the midline to a depth of $4.5 \mathrm{~mm}$ from the skull surface. Animals were maintained for 4 to 7 days to ensure dye transport to RGC somas before proceeding with experiments (Figure 3B).

\section{In Vivo Confocal Laser Scanning Ophthalmoscopy}

A Heidelberg Retinal Angiogram 2 (Heidelberg Engineering, Heidelberg, Germany) confocal scanning laser ophthalmoscope (CSLO) was used for in vivo imaging of the rat retina. Briefly, rats were anesthetized and their pupils were dilated with phenylephrine and atropine. The 488-nm laser was used for the excitation of cells positive for $\mathrm{OH}-\mathrm{Et}$ (the product of the reaction of superoxide with hydroethidine) and 4-Di-10-Asp retrograde-labeled RGC somas. To ensure that the plane of focus was in the ganglion cell layer, the CSLO polarization filter (red-free mode) was used to focus onto the nerve fiber layer and then adjusted posteriorly. Retinal images were captured using a 30-degree field-of-view lens, with real-time averaging of at least 50 images. For each study time point, eight images of each retinal octant adjacent to the optic nerve head (superior, superior nasal, nasal, inferior nasal, inferior, inferior 


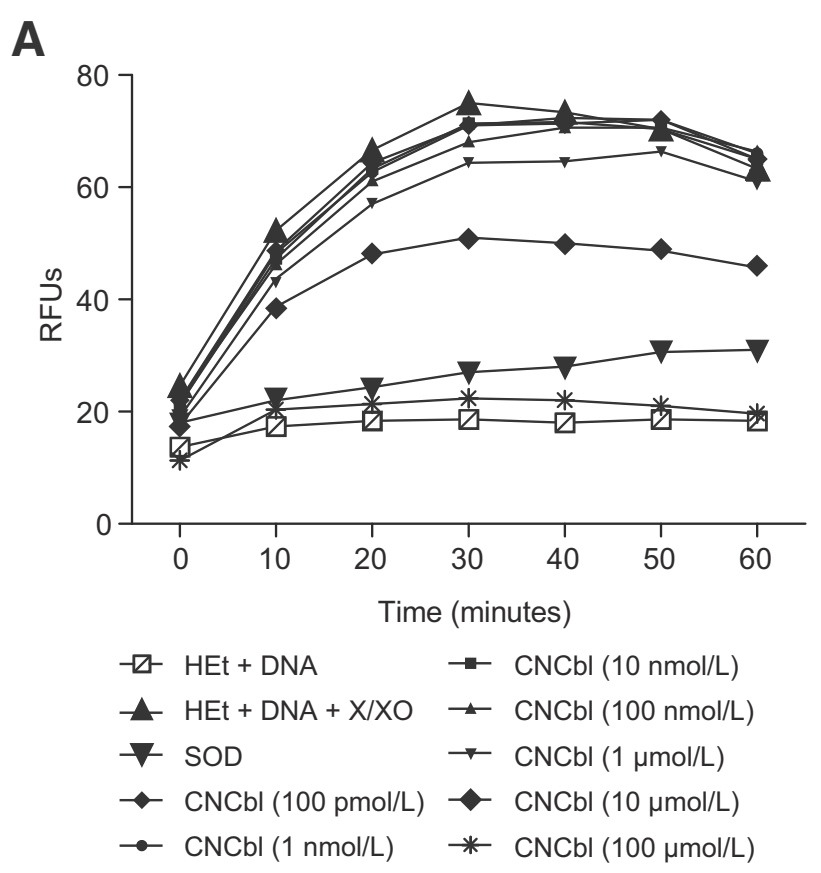

B

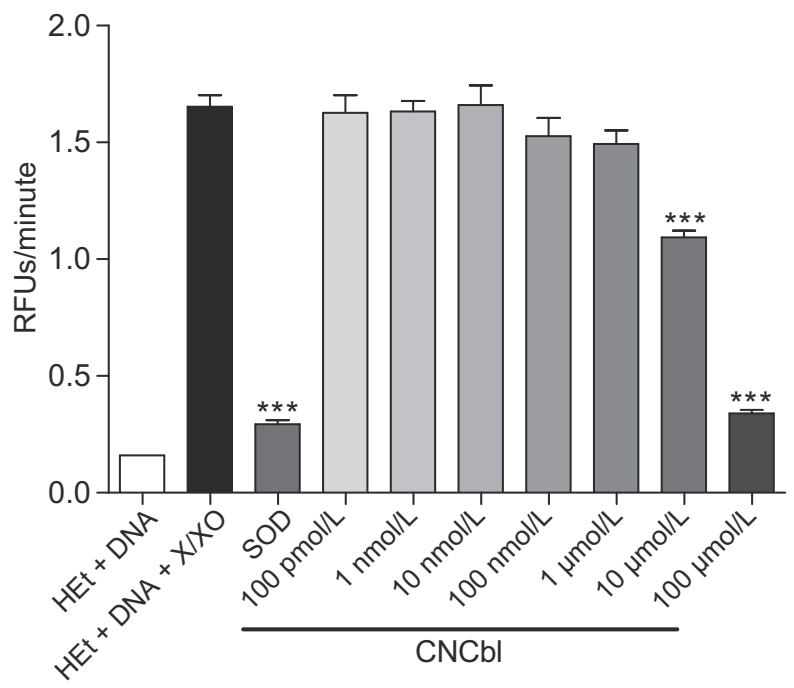

Figure 4 Superoxide scavenging capacity of cobalamin in a cell-free system. Hydroethidine (HEt; $100 \mu \mathrm{mol} / \mathrm{L}$ ) was incubated with superoxide generated by xanthine/xanthine oxidase $(X / X 0)$, in the presence of $1 \mathrm{mg} /$ $\mathrm{mL}$ salmon sperm DNA, to provide a substrate for 2-hydroxyethidium $(\mathrm{OH}-\mathrm{Et})$ binding and fluorescence emission. A: In the absence of superoxide dismutase (SOD) or cyanocobalamin (CNCbl), the relative fluorescence units (RFUs) of the reaction between superoxide and HEt reached the maximum at 30 minutes. Addition of $0.36 \mathrm{U} / \mathrm{mL}$ SOD or $100 \mathrm{pmol} / \mathrm{L}$ to 100 $\mu \mathrm{mol} / \mathrm{L} \mathrm{CNCbl}$ prevented the increase in fluorescence by scavenging superoxide. B: Comparison of the slope (RFUs/minute) from the first 30 minutes of each reaction. The larger values indicate higher superoxide availability, leading to greater $\mathrm{OH}$-Et fluorescence. The slope was significantly lower in the presence of SOD or CNCbl, indicating that they scavenged superoxide. ${ }^{* * *} P<0.001$ versus $\mathrm{HEt}+\mathrm{DNA}+\mathrm{X} / \mathrm{X} 0$.

temporal, temporal, and superior temporal) were taken at each experimental time point for each animal. An observer (M.-M.C.) masked to the treatment group counted 4-Di-10Asp-labeled RGCs in all retinal octants using an identical rectangular grid. The grid was always positioned relative to one of the major identifiable vessels to enable assessment of RGC numbers at the same location over time (Figure 3C). OH-Et-positive RGCs were counted 4 days after optic nerve transection. The number of RGCs counted in vivo in retinas by CSLO was the same as the number of retrogradelabeled RGCs counted by fluorescent microscopy in the same retinas after fixation and whole mounting (Table 1).

\section{Statistical Analysis}

Unpaired $t$-tests were used to compare means from two groups, with $\alpha=0.05$. For comparisons between multiple groups, significance was calculated using one-way analysis of variance, followed by the Dunnett multiple comparison post-hoc test at $\alpha=0.05$ against the vehicle control group. Data are presented as means \pm SEM, unless otherwise indicated.

\section{Results}

\section{Cobalamin Scavenges Superoxide in a Cell-Free System}

The relative fluorescence units of the reaction between HEt and superoxide generated from xanthine/xanthine oxidase was measured to determine the degree of superoxide scavenging by $\mathrm{CNCbl}$ compared with SOD. ${ }^{44} \mathrm{HEt}$ is oxidized by superoxide to $\mathrm{OH}-\mathrm{Et}$ and becomes fluorescent (excitation, $395 \mathrm{~nm}$; emission, $567 \mathrm{~nm}$ ). ${ }^{45}$ This reaction approaches maximal fluorescence at 30 minutes (Figure 4A). To compare superoxide scavenging by $\mathrm{CNCbl}(100 \mathrm{pmol} / \mathrm{L}$ to $100 \mu \mathrm{mol} / \mathrm{L})$ to bovine erythrocyte SOD $(0.36 \mathrm{U} / \mathrm{mL})$, the slope from the first 30 minutes of each reaction was calculated and compared the rate (relative fluorescence units/minute) of superoxide production in the presence or absence of scavenger. Numerically, larger slopes indicated more superoxide reacting with $\mathrm{HEt}$ to yield fluorescent $\mathrm{OH}-$ $\mathrm{Et}$, indicating less superoxide scavenging occurred, whereas smaller slopes indicated greater scavenging. The slope with the positive-control SOD was significantly less than the noscavenger control $(0.29 \pm 0.018$ versus $1.65 \pm 0.049$ relative fluorescence units/minute; $P<0.0001$ ), indicating $82 \%$ of available superoxide was scavenged. The slopes with $\mathrm{CNCbl}(10$ or $100 \mu \mathrm{mol} / \mathrm{L})$ were also significantly less than the no-scavenger control $(1.09 \pm 0.030$ and $0.34 \pm 0.0058$ relative fluorescence units/minute, respectively; $P<0.0001$ for both comparisons), and indicated scavenging of $34 \%$ and $79 \%$ of available superoxide, respectively (Figure 4B).

\section{Cobalamin Scavenges Superoxide in Neuronal Cells in Vitro}

Differentiated 661W/RGC-5 cells were treated with menadione to generate intracellular superoxide via mitochondrial reduction-oxidation cycling. ${ }^{35} \mathrm{HEt}$ can passively diffuse across the plasma membrane of live cells to react with intracellular superoxide, followed by binding to nuclear 
A
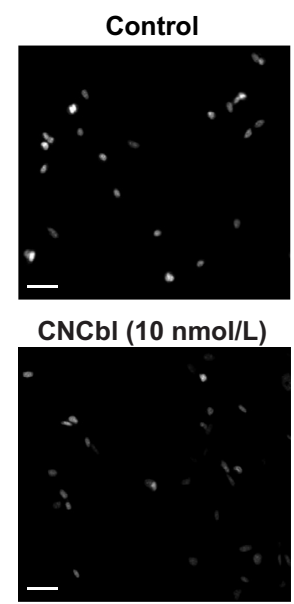

PEG-SOD

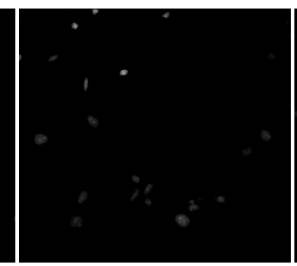

CNCbI $(1 \mu \mathrm{mol} / \mathrm{L})$
CNCbl (100 pmol/L)

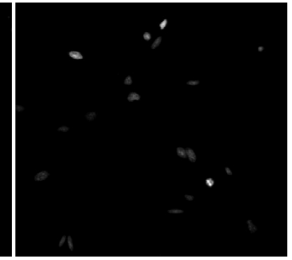

CNCbl $(100 \mu \mathrm{mol} / \mathrm{L})$

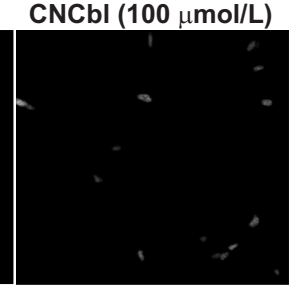

B

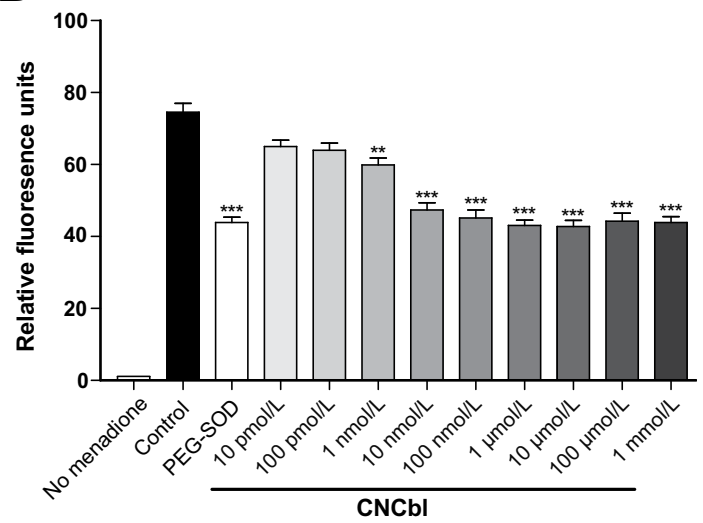

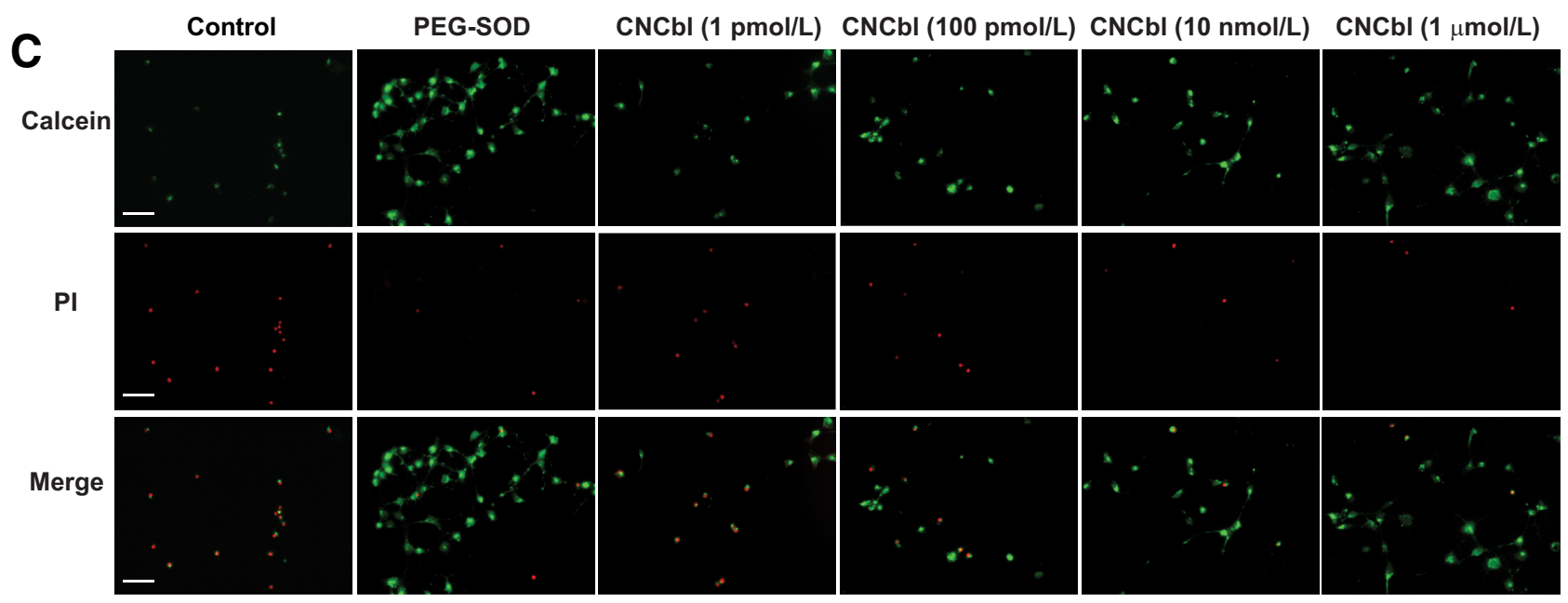

D

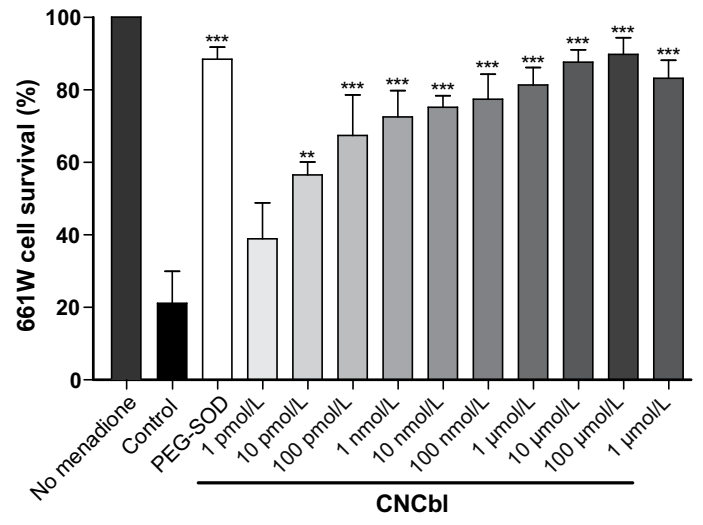

Figure 5 Cobalamin scavenges superoxide and is neuroprotective in vitro in menadione-treated 661 W/RGC-5 cells. Differentiated 661 W/RGC- 5 cells were treated with $15 \mu \mathrm{mol} / \mathrm{L}$ menadione for 24 hours to generate superoxide in the presence or absence of cyanocobalamin (CNCbl). A: Representative microscope images of 2hydroxyethidium (OH-Et)-stained $661 \mathrm{~W} / \mathrm{RGC}-5$ cells. The fluorescence is localized in the nucleus. B: Graph summarizing $\mathrm{OH}$-Et levels of $661 \mathrm{~W} / \mathrm{RGC}-5$ cells. CNCbl concentrations $>1 \mu \mathrm{mol} / \mathrm{L}$ do not demonstrate greater superoxide scavenging. C: Representative microscope images of $661 \mathrm{~W} / \mathrm{RGC}-5$ cells stained with calcein (green) and propidium iodide (PI; red). D: Graph summarizing the percentage of cell survival. ${ }^{* *} P<0.01,{ }^{* * *} P<0.001$ versus controls. Scale bars $=50 \mu \mathrm{m}$ (A and $\left.\mathbf{C}\right)$. PEG-S0D, pegylated superoxide dismutase.

DNA to yield a fluorescent signal in the nucleus. Quantification of the nuclear fluorescence, therefore, is an indirect measure of superoxide levels. Compared with cells exposed to menadione in the absence of a scavenger, cells treated with $\mathrm{CNCbl}$ concentrations, from $1 \mathrm{nmol} / \mathrm{L}$ to $100 \mu \mathrm{mol} / \mathrm{L}$, had significantly decreased levels of superoxide (Figure 5A). Superoxide levels of menadione-treated 661W/ RGC-5 cells decreased in the presence of CNCbl, with $20 \%$ scavenging at $1 \mathrm{nmol} / \mathrm{L}$ and $42 \%$ scavenging at $1 \mu \mathrm{mol} / \mathrm{L}$
(Figure 5B). Higher concentrations of $\mathrm{CNCbl}$ did not demonstrate greater superoxide scavenging.

\section{Cobalamin Increases Survival of Neuronal Cells in Vitro}

Differentiated 661W/RGC-5 cells were treated with $15 \mu \mathrm{mol} / \mathrm{L}$ menadione to generate superoxide in the presence or absence of $1 \mathrm{pmol} / \mathrm{L}$ to $1 \mathrm{mmol} / \mathrm{L} \mathrm{CNCbl}$ or $30 \mathrm{U} / \mathrm{mL}$ PEG-SOD as a positive control, then stained with calcein-AM and propidium 

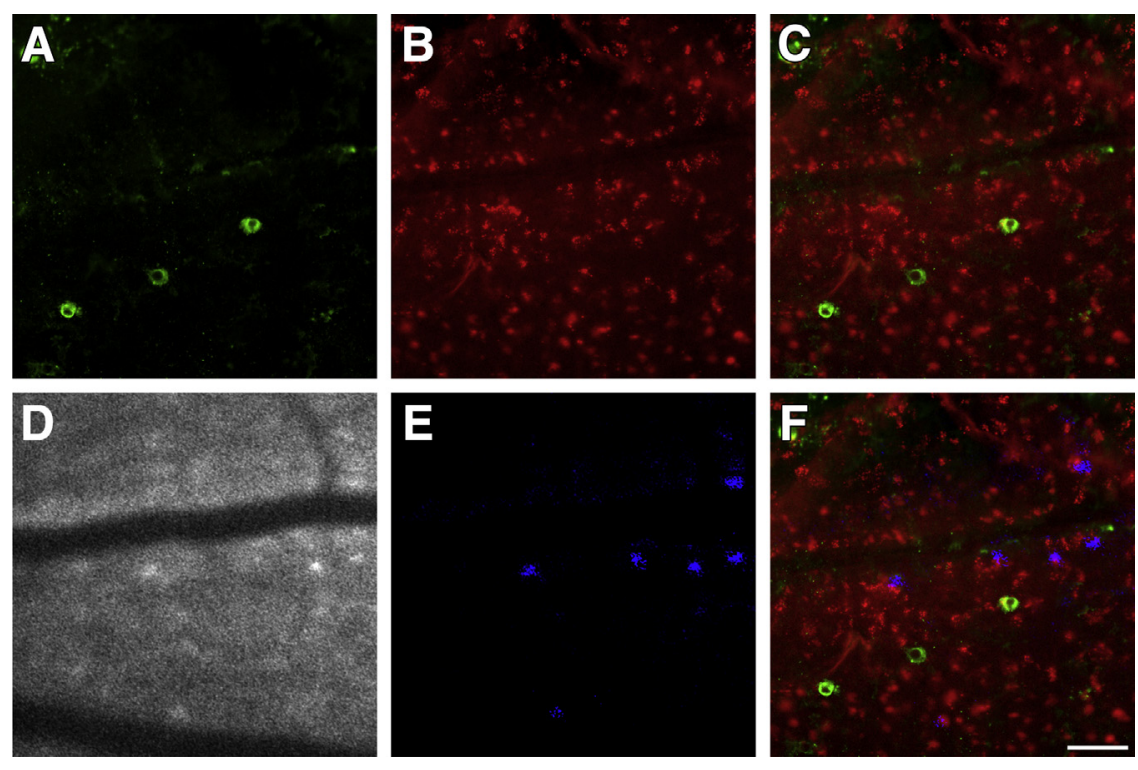

Figure 6 Superoxide detected with hydroethidine colocalizes with 1,1'-dioctadecyl3,3,3', 3'-tetramethylindotricarbocyanine iodide (DiR)-labeled retinal ganglion cells (RGCS) and not with ionized calcium-binding adapter molecule 1 (Iba-1)-labeled microglia. A: Microglia (green) detected with antibodies to Iba-1 in a whole mount of a retina after optic nerve transection. B: The same retina with $\mathrm{RGCS}$ (red) retrogradely labeled with DiR. C: Overlay of RGCs (red) and microglia (green). D: Confocal scanning laser ophthalmoscopy (CSLO) image demonstrating 2hydroxyethidium (OH-Et)-

positive cells in vivo. E: The same CSLO image processed with pseudocolored $\mathrm{OH}$-Et-positive cells (blue). F: The same locations in the retinal whole mount and the CSLO image were registered with respect to the retinal vessels, and an overlay image of all three images was generated. Only RGCs, and not microglia, correspond to $\mathrm{OH}-\mathrm{Et}-$ positive cells (purple areas). Scale bar $=50 \mu \mathrm{m}$ (A-F). iodide to assess cell survival (Figure 5C). Cells exposed to menadione in the absence of CNCbl or PEG-SOD had a mean survival of $21.2 \% \pm 8.8 \%$. The survival of $661 \mathrm{~W} / \mathrm{RGC}-5$ cells increased significantly in the presence of $10 \mathrm{pmol} / \mathrm{L} \mathrm{CNCbl}$ (56.5\% $\pm 3.6 \% ; P<0.001$ compared with control), and increased to $87.7 \% \pm 3.4 \%(P<0.0001)$ with $10 \mu \mathrm{mol} / \mathrm{L}$ $\mathrm{CNCbl}$ (Figure 5D). Higher concentrations of $\mathrm{CNCbl}$ $(100 \mu \mathrm{mol} / \mathrm{L})$ resulted in $661 \mathrm{~W} / \mathrm{RGC}-5$ cell survival comparable to cells treated with PEG-SOD.

\section{Cobalamin Scavenges Superoxide in Retinal Ganglion Cells after Optic Nerve Transection in Vivo}

To determine whether cobalamin was a superoxide scavenger in vivo, we took advantage of our ability to use confocal scanning laser ophthalmoscopy to longitudinally image superoxide in axotomized rat RGCs. ${ }^{36,39}$ To confirm that superoxide detected as the reaction product $\mathrm{OH}-\mathrm{Et}$ was associated with RGCs and not microglia, RGCs were retrograde labeled by injection of $1,1^{\prime}$-dioctadecyl-3,3,3',3'-tetramethylindotricarbocyanine iodide (DiR) into the superior colliculus, and 7 days later, the optic nerve was transected. An intravitreal injection of HEt was performed 3 days after transection, and 24 hours later, the retina was imaged in vivo by CSLO to detect $\mathrm{OH}-$ Et-positive cells. Immediately after CSLO imaging, the animal was euthanized and the retina was fixed and processed for immunostaining against the microglial marker ionized calciumbinding adapter molecule 1 (Iba-1). $\mathrm{OH}-\mathrm{Et}-$ positive cells were associated with DiR-positive RGCs and not Iba-1-positive microglia (Figure 6).

To study the effect of cobalamin on superoxide in RGCs, HEt was injected into the vitreous 3 days after optic nerve transection in Long-Evans rats, in the presence or absence of CNCbl, using four injection paradigms with different concentrations and timing of administration. Exposure of retinas to laser excitation from the CSLO alone does not cause HEt oxidation (Supplemental Figure S1). Injecting $4 \mu \mathrm{L}$ of $10 \mathrm{mmol} / \mathrm{L} \mathrm{CNCbl}$ (final intravitreal concentration, $667 \mu \mathrm{mol} / \mathrm{L}$ ) 1 day after transection decreased the number of $\mathrm{OH}-\mathrm{Et}-$ positive cells to $44.2 \pm 6.1(n=6)$, compared with $77.3 \pm 7.4(n=10)$ in the vehicle-control group (39\% decrease; $P=0.003$ ). Injection of a lower $\mathrm{CNCbl}$ dose $(4 \mu \mathrm{L}$ of $5 \mathrm{mmol} / \mathrm{L}$; final intravitreal concentration, $333 \mu \mathrm{mol} / \mathrm{L}$ ) at days 1 or 3 after transection did not reduce the number of superoxide-positive cells (Figure 7, A and B). The greatest decrease in $\mathrm{OH}-\mathrm{Et}-$ positive cells after axotomy $[34.7 \pm 3.8(n=9) ; 55 \%$ decrease; $P<0.0001]$ occurred when an initial $667 \mu \mathrm{mol} / \mathrm{L} \mathrm{CNCbl}$ dose on day 1 was followed by a delayed $333 \mu \mathrm{mol} / \mathrm{L} \mathrm{CNCbl}$ dose on day 3 (Figure 7, A and B).

\section{Cobalamin Increases the Survival of Retinal Ganglion Cells after Optic Nerve Transection in Vivo}

RGCs were retrograde labeled by injection of 4-Di-10-Asp into the superior colliculi 4 to 7 days before optic nerve transection. The first group of rats received an intravitreal injection of $667 \mu \mathrm{mol} / \mathrm{L} \mathrm{CNCbl} 1$ day after transection of the optic nerve and were longitudinally imaged by CSLO over 14 days to monitor RGC survival (Figure 7, C and D). Another group was injected with vehicle control and similarly longitudinally imaged to monitor RGC survival. At 5 days after transection, the survival of RGCs in rats that received an intravitreal injection of $667 \mu \mathrm{mol} / \mathrm{L} \mathrm{CNCbl} \mathrm{was}$ $87.0 \% \pm 2.6 \%(n=9)$, compared with $69.0 \% \pm 3.7 \%$ ( $n=9 ; P=0.0008$ ) in the vehicle-control group. At 7 days after transection, RGC survival in CNCbl-treated retinas was $79.7 \% \pm 2.5 \%(n=9)$, compared with $53.1 \% \pm 2.3 \%$ ( $n=9 ; P<0.0001)$ in the vehicle-control group. Finally, at 14 days after transection, 59.7\% $\pm 3.3 \%(n=9)$ of RGCs in CNCbl-treated retinas survived, compared with 
A

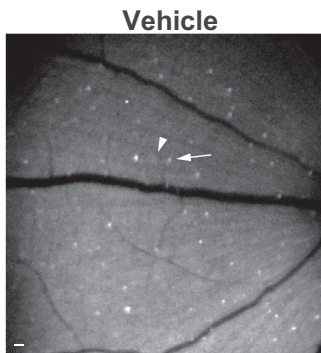

Early $\mathrm{CNCbl}$

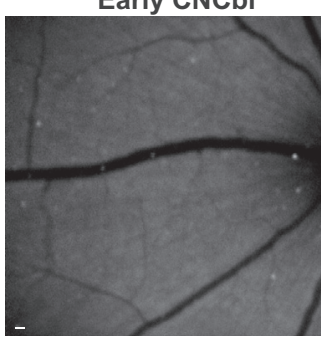

C
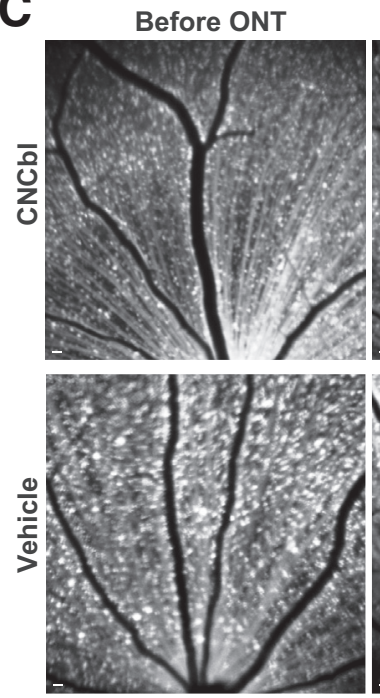

Late $\mathrm{CNCb}$

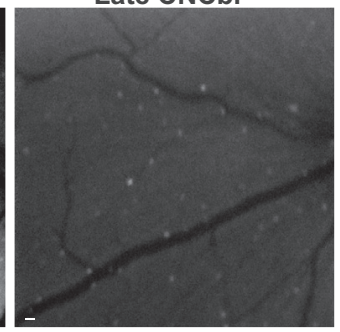

Early + late $\mathrm{CNCbl}$

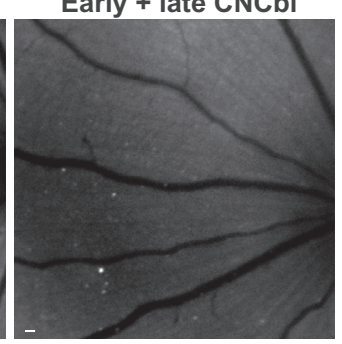

5 days
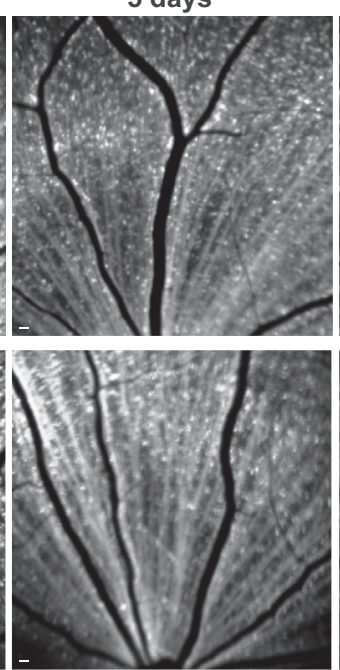

B

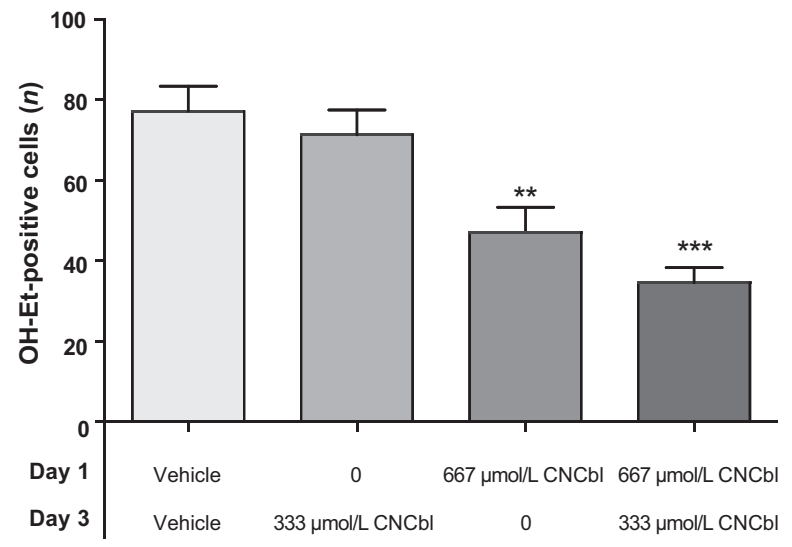

Figure 7 Cobalamin scavenges superoxide and is neuroprotective in vivo in rats with unilateral optic nerve transection (ONT). A: Representative confocal scanning laser ophthalmoscopy (CSLO) images of 2-hydroxyethidium (OH-Et)-positive cells 4 days after optic nerve transection. In the vehicle, an example of a cell considered positive is indicated with an arrow, and an area of indistinct fluorescence considered negative is indicated with an arrowhead. Retinas treated with cyanocobalamin ( $\mathrm{CNCbl}$ ) have fewer $\mathrm{OH}$-Et-positive cells compared with those treated with vehicle. B: Graph summarizing the number of $\mathrm{OH}$ Et-positive cells with respect to CNCbl treatment. C: Representative CSLO images of labeled retinal ganglion cells (RGCs) treated with CNCbl or vehicle control before transection and at 5 and 7 days after transection. D: Graph summarizing percentage of RGC survival at 5, 7, and 14 days after transection (D5, D7, and D14, respectively) when treated with $667 \mu \mathrm{mol} / \mathrm{L} \mathrm{CNCbl}$ or vehicle. $n=6$ (B, vehicle); $n=8(\mathbf{B}, 333 \mu \mathrm{mol} / \mathrm{L} \mathrm{CNCbl}) ; n=10(\mathbf{B}, 667 \mu \mathrm{mol} / \mathrm{L} \mathrm{CNCbl}) ; n=9$ (B, $333+667 \mu \mathrm{mol} / \mathrm{L} \mathrm{CNCbl,} \mathrm{and} \mathbf{D}$, all groups). ${ }^{* *} P<0.01,{ }^{* *} P<0.001$ versus vehicles. Scale bars $=200 \mu \mathrm{m}(\mathbf{A}$ and $\mathbf{C})$.

$29.3 \% \pm 2.3 \%(n=9 ; P<0.0001)$ survival in the vehiclecontrol group (Figure 7, C and D).

\section{Discussion}

These data demonstrate the following: i) cobalamin scavenges superoxide generated in a cell-free reaction between xanthine and xanthine oxidase; ii) cobalamin scavenges intracellular superoxide induced by menadione-induced reduction-oxidation cycling and protects against cell death in vitro; and iii) cobalamin scavenges superoxide and is neuroprotective in vivo in rat RGCs after optic nerve transection. To the best of our knowledge, this is the first in vivo demonstration that cobalamin scavenges superoxide and is neuroprotective for neuronal cells.

Previous reaction kinetic studies have shown that cobalamin reacts with superoxide in a second-order reaction to generate hydrogen peroxide at a rate of $7 \times 10^{8} \mathrm{~mol} / \mathrm{L}$ per second, which is comparable to the SOD-catalyzed rate of $2 \times 10^{9} \mathrm{~mol} / \mathrm{L}$ per second. ${ }^{30}$ The same group also demonstrated in vitro superoxide scavenging by cobalamin in an endothelial cell line. Clinically, patients with genetic cobalamin metabolism disorders have significantly greater 
levels of markers for oxidative stress in their urine. ${ }^{47}$ Fibroblast cell lines from patients with methylmalonic aciduria cobalamin deficiency type $\mathrm{C}(\mathrm{cblC})$ with homocystinuria had significantly increased levels of reactive oxygen species and cell death, whereas the wild-type expression of these genes reversed the reactive oxygen species elevation. ${ }^{48}$ Incubation of these cell lines with hydroxocobalamin decreased the reactive oxygen species levels in cultured cells. ${ }^{48}$ These observations suggest a role for an underlying mechanism because of the lack of superoxide scavenging by cobalamin. Together with the results from our study demonstrating that cobalamin scavenges superoxide and is neuroprotective in neuronal cells, these findings suggest that cobalamin contributes to the maintenance of cellular reduction-oxidation status in addition to its known function as a cofactor in metabolic processes.

Such findings provide a pathophysiological explanation for an uncommon, but potentially devastating, disease, the optic neuropathy caused by vitamin $\mathrm{B}_{12}$ deficiency. This deficiency has well-known neurological manifestations, with peripheral neuropathy, subacute combined (posterior and lateral columns) degeneration of the spinal cord, cognitive changes, and optic neuropathy being the most prominent. The damage from vitamin $\mathrm{B}_{12}$ deficiency within the retina is specific to RGCs and spares photoreceptors and other retinal neurons on clinical and pathologic grounds. ${ }^{49}$ A unifying explanation for the pathophysiology of vitamin $\mathrm{B}_{12}$ deficiency in the eye would explain why it is restricted to RGCs. It is unlikely to be a result of insufficient production of ATP because genetic mitochondrial diseases, such as mitochondrial DNA deletions, ${ }^{50}$ mitochondrial encephalomyopathy, lactic acidosis, and stroke-like episodes, and neuropathy, ataxia, and retinitis pigmentosa, ${ }^{51}$ affect high energy-consuming tissues (eg, skeletal muscle and photoreceptors), but not RGCs. ${ }^{52,53}$

Instead, on the basis of the results of the present study, we propose that the specificity of vitamin $\mathrm{B}_{12}$ deficiency for RGCs is because this molecule is a superoxide scavenger within RGCs, and RGCs are particularly sensitive to superoxide-induced cell death. We previously showed that RGCs use superoxide as an intracellular signaling molecule to transduce apoptosis after axonal injury, ${ }^{36}$ based on our findings that superoxide is generated in RGCs after axotomy $^{34}$ and that superoxide generation can occur before apoptosis in neuronal cells. ${ }^{36,54}$ The difference in excitation spectrum between OH-Et (the product of HEt and superoxide) and Et (the product of a single electron reaction with HEt) to distinguish the two in RGCs after optic nerve transection was used. It was shown that intravitreal application of pegylated SOD eliminates the axotomy-induced fluorescence. ${ }^{36}$ Using retrograde DiR labeling combined with HEt staining, OH-Et fluorescence colocalized with DiR-labeled RGCs, confirming that superoxide generation is restricted to RGCs. ${ }^{36}$ There was no OH-Et colocalization with Griffonia (Bandeiraea) simplicifolia lectin I, indicating that macrophages and microglia were not the source of $\mathrm{OH}$ $\mathrm{Et}-$ positive cells in our experiments. ${ }^{36}$ Drugs that scavenge superoxide also decrease RGC death. ${ }^{39,55}$ Conversely, induction of elevated superoxide by knockdown of superoxide dismutase isoforms induces neuronal or RGC death. ${ }^{56,57}$ Together, these previous studies demonstrated that superoxide is generated in RGCs after axotomy. Given the present findings that cobalamin is a neuronal superoxide scavenger in vitro and in vivo, vitamin $\mathrm{B}_{12}$ deficiency would be expected to lead to deregulated superoxide levels in RGCs. Because superoxide is an axotomy signal and induces RGC death, this provides a hypothetical mechanism for optic neuropathy in vitamin $\mathrm{B}_{12}$ deficiency: RGCs are relatively sensitive to superoxide. ${ }^{34,36}$

RGCs, like all cells, contain SOD-1 in the cytoplasm and SOD-2 in the mitochondria. ${ }^{58}$ These endogenous superoxide scavengers would have to be overwhelmed in vitamin $B_{12}$ deficiency, and would occur in situations where there are high levels of mitochondrial oxygen consumption and consequent superoxide leak from the mitochondrial electron transport chain. ${ }^{59}$ RGCs have high numbers of mitochondria in the unmyelinated portion of their axons, particularly at the optic nerve head anterior to the myelin transition zone. ${ }^{60,61}$ More mitochondria are needed in unmyelinated than myelinated axons because the lower membrane resistance and higher capacitance necessitate larger current flux for axonal conduction. Therefore, the prelaminar and laminar portions of the optic nerve head are putative hot spots for superoxidemediated damage resulting from vitamin $\mathrm{B}_{12}$ deficiency.

Support for a superoxide-dependent mechanism comes from a seemingly unrelated optic neuropathy, Leber hereditary optic neuropathy, which shares with vitamin $B_{12}$ deficiency neuropathy an uncommon clinical phenotype, a cecocentral scotoma visual field defect. ${ }^{62}$ This maternally inherited optic neuropathy results from one of three mutations in mitochondrial DNA coding for subunits of complex I of the mitochondrial electron transport chain, and causes relatively specific damage to RGCs, with minimal effects elsewhere in the retina, central nervous system, or body. ${ }^{63}$ The Leber hereditary optic neuropathy mutations do not significantly decrease ATP production in studies of fibroblast cybrids. ${ }^{64}$ However, they greatly increase superoxide levels, and it is more likely that the superoxide induction is responsible for the RGC-specific death in Leber hereditary optic neuropathy. ${ }^{52}$

It is possible that cobalamin has an indirect effect on the levels of cellular superoxide by regulating other signaling pathways. For example, vitamin $B_{12}$ deficiency induces a significant increase in levels of tumor necrosis factor- $\alpha^{65,66}$ and activated NF- $\kappa B^{67}$ in rat spinal cord tissue. Consequently, pathways downstream of NF- $\kappa \mathrm{B}$, which are involved in regulating reactive oxygen species levels in cells, may be affected, resulting in production or scavenging of superoxide. ${ }^{68}$ Alternatively, cobalamin availability may be decreased by high levels of intracellular superoxide if its corrin ring is decomposed by oxidation, leaving the cobalamin unable to act as a coenzyme. ${ }^{69}$ 
Our study has limitations. First, the in vitro studies were performed with 661W/RGC-5 cells, which are cone photoreceptor-like retinal neurons that can be differentiated into cells with an axonal phenotype. When these studies were performed, the cell line was misidentified as RGC-5 cells, but subsequently the 661W/RGC-5 and RGC-5 cell lines have been shown to be highly related. ${ }^{43,70}$ Second, an optic nerve transection model (which only affects RGCs) was used in rats to investigate whether cobalamin can scavenge superoxide and increase cell survival in vivo, with the added advantage of monitoring how transected RGCs respond to intravitreal injections of cobalamin in the same animal over time. Optic nerve transection is an acute injury and is a model for diseases like traumatic optic neuropathy. The findings from optic nerve studies are not necessarily extrapolatable to the spinal cord, peripheral nerves, and cerebral cortex, areas that are also clinically affected by vitamin $\mathrm{B}_{12}$ deficiency. Third, these data do not definitively prove that vitamin $B_{12}$ deficiency causes RGC death mediated by superoxide. It is difficult to prove this because lower animals, such as rodents, have almost completely large-fiber RGCs; however, it is the small-fiber RGCs that are affected in vitamin $B_{12}$ deficiency. The rats were maintained on a vitamin $\mathrm{B}_{12}$-deficient diet for more than a year, yet the degree of optic neuropathy that they developed was minimal (L.A.L., unpublished data). Primates have large numbers of small fibers, but it is ethically challenging to chronically deprive nonhuman primates of vitamin $\mathrm{B}_{12}$. Nonetheless, the data presented demonstrate that cobalamin is both a superoxide dismutase and a neuroprotectant in axotomized RGCs.

In summary, cobalamin scavenges superoxide and is neuroprotective for RGCs after axonal injury in vivo. These results extend the results of previous studies ${ }^{29-31}$ to neurons, demonstrating a novel role for cobalamin in maintaining cellular reduction-oxidation status, and support the hypothesis that vitamin $\mathrm{B}_{12}$ deficiency optic neuropathy results from a misplaced signal for cell death because of unconstrained superoxide generation. These results also have implications for the ocular health of populations at risk of vitamin $B_{12}$ deficiency, most notably elderly people, vegans, and third-world populations. Further study examining the prevalence of vitamin $\mathrm{B}_{12}$ deficiency in patients with optic neuropathies may prove informative for implementing preventative therapy for high-risk populations.

\section{Supplemental Data}

Supplemental material for this article can be found at https://doi.org/10.1016/j.ajpath.2017.08.032.

\section{References}

1. Quigley HA: Number of people with glaucoma worldwide. Br J Ophthalmol 1996, 80:389-393
2. Quigley HA, Broman AT: The number of people with glaucoma worldwide in 2010 and 2020. Br J Ophthalmol 2006, 90:262

3. Dirani M, Crowston JG, Taylor PS, Moore PT, Rogers S, Pezzullo ML, Keeffe JE, Taylor HR: Economic impact of primary open-angle glaucoma in Australia. Clin Exp Ophthalmol 2011, 39: 623-632

4. Davis BM, Crawley L, Pahlitzsch M, Javaid F, Cordeiro MF: Glaucoma: the retina and beyond. Acta Neuropathol 2016, 132:807-826

5. Selles-Navarro I, Villegas-Perez MP, Salvador-Silva M, RuizGomez JM, Vidal-Sanz M: Retinal ganglion cell death after different transient periods of pressure-induced ischemia and survival intervals: a quantitative in vivo study. Invest Ophthalmol Vis Sci 1996, 37: 2002-2014

6. Danesh-Meyer HV, Papchenko T, Savino PJ, Law A, Evans J, Gamble GD: In vivo retinal nerve fiber layer thickness measured by optical coherence tomography predicts visual recovery after surgery for parachiasmal tumors. Invest Ophthalmol Vis Sci 2008, 49: 1879-1885

7. Trip SA, Schlottmann PG, Jones SJ, Altmann DR, Garway-Heath DF, Thompson AJ, Plant GT, Miller DH: Retinal nerve fiber layer axonal loss and visual dysfunction in optic neuritis. Ann Neurol 2005, 58: 383-391

8. Steinsapir KD: Traumatic optic neuropathy. Curr Opin Ophthalmol 1999, 10:340-342

9. Whatham A, Bartlett H, Eperjesi F, Blumenthal C, Allen J, Suttle C, Gaskin K: Vitamin and mineral deficiencies in the developed world and their effect on the eye and vision. Ophthalmic Physiol Opt 2008, 28:1-12

10. Gorusupudi A, Nelson K, Bernstein PS: The age-related eye disease 2 study: micronutrients in the treatment of macular degeneration. Adv Nutr 2017, 8:40-53

11. Chew EY: Nutrition effects on ocular diseases in the aging eye. Invest Ophthalmol Vis Sci 2013, 54:ORSF42-ORSF47

12. Cohen H: Optic atrophy as the presenting sign in pernicious anaemia. Lancet 1936, 228:1202-1203

13. Larner AJ: Visual failure caused by vitamin B12 deficiency optic neuropathy. Int J Clin Pract 2004, 58:977-978

14. Oh R, Brown DL: Vitamin B12 deficiency. Am Fam Physician 2003 , 67:979-986

15. Herbert V: Vitamin B-12: plant sources, requirements, and assay. Am J Clin Nutr 1988, 48:852-858

16. Watanabe F: Vitamin B12 sources and bioavailability. Exp Biol Med (Maywood) 2007, 232:1266-1274

17. Alpers DH, Russell-Jones G: Gastric intrinsic factor: the gastric and small intestinal stages of cobalamin absorption: a personal journey Biochimie 2013, 95:989-994

18. Fyfe JC, Madsen M, Hojrup P, Christensen EI, Tanner SM, de la Chapelle A, He Q, Moestrup SK: The functional cobalamin (vitamin B12)-intrinsic factor receptor is a novel complex of cubilin and amnionless. Blood 2004, 103:1573-1579

19. Kozyraki R, Fyfe J, Kristiansen M, Gerdes C, Jacobsen C, Cui S, Christensen EI, Aminoff M, de la Chapelle A, Krahe R, Verroust PJ, Moestrup SK: The intrinsic factor-vitamin B12 receptor, cubilin, is a high-affinity apolipoprotein A-I receptor facilitating endocytosis of high-density lipoprotein. Nat Med 1999, 5:656-661

20. Quadros EV, Sequeira JM: Cellular uptake of cobalamin: transcobalamin and the TCbIR/CD320 receptor. Biochimie 2013, 95:1008-1018

21. Gherasim C, Hannibal L, Rajagopalan D, Jacobsen DW, Banerjee R: The C-terminal domain of CblD interacts with $\mathrm{CblC}$ and influences intracellular cobalamin partitioning. Biochimie 2013, 95:1023-1032

22. Banerjee R: B12 trafficking in mammals: a for coenzyme escort service. ACS Chem Biol 2006, 1:149-159

23. Gruber K, Puffer B, Krautler B: Vitamin B12-derivatives-enzyme cofactors and ligands of proteins and nucleic acids. Chem Soc Rev 2011, 40:4346-4363

24. Froese DS, Gravel RA: Genetic disorders of vitamin B(1)(2) metabolism: eight complementation groups-eight genes. Expert Rev Mol Med 2010, 12:e37 
25. Lerner-Ellis JP, Tirone JC, Pawelek PD, Dore C, Atkinson JL, Watkins D, Morel CF, Fujiwara TM, Moras E, Hosack AR, Dunbar GV, Antonicka H, Forgetta V, Dobson CM, Leclerc D, Gravel RA, Shoubridge EA, Coulton JW, Lepage P, Rommens JM, Morgan K, Rosenblatt DS: Identification of the gene responsible for methylmalonic aciduria and homocystinuria, cblC type. Nat Genet 2006, 38:93-100

26. Bonafede L, Ficicioglu CH, Serrano L, Han G, Morgan J, Mills MD, Forbes BJ, Davidson SL, Binenbaum G, Kaplan PB, Nichols CW, Verloo P, Leroy BP, Maguire AM, Aleman TS: Cobalamin C deficiency shows a rapidly progressing maculopathy with severe photoreceptor and ganglion cell loss. Invest Ophthalmol Vis Sci 2015, 56: $7875-7887$

27. Weisfeld-Adams JD, McCourt EA, Diaz GA, Oliver SC: Ocular disease in the cobalamin $\mathrm{C}$ defect: a review of the literature and a suggested framework for clinical surveillance. Mol Genet Metab 2015, 114:537-546

28. Ku CA, Ng JK, Karr DJ, Reznick L, Harding CO, Weleber RG, Pennesi ME: Spectrum of ocular manifestations in cobalamin $\mathrm{C}$ and cobalamin A types of methylmalonic acidemia. Ophthalmic Genet 2016, 37:404-414

29. Birch CS, Brasch NE, McCaddon A, Williams JH: A novel role for vitamin $\mathrm{B}(12)$ : cobalamins are intracellular antioxidants in vitro. Free Radic Biol Med 2009, 47:184

30. Suarez-Moreira E, Yun J, Birch CS, Williams JH, McCaddon A, Brasch NE: Vitamin $\mathrm{B}(12)$ and redox homeostasis: cob(II)alamin reacts with superoxide at rates approaching superoxide dismutase (SOD). J Am Chem Soc 2009, 131:15078

31. Suarez-Moreira E, Brasch NE, Yun J: Vitamin B12 protects against superoxide-induced cell injury in human aortic endothelial cells. Free Radic Biol Med 2011, 51:876-883

32. Turrens JF: Mitochondrial formation of reactive oxygen species. J Physiol 2003, 552:335-344

33. Johnson F, Giulivi C: Superoxide dismutases and their impact upon human health. Mol Aspects Med 2005, 26:340-352

34. Lieven CJ, Schlieve CR, Hoegger MJ, Levin LA: Retinal ganglion cell axotomy induces an increase in intracellular superoxide anion. Invest Ophthalmol Vis Sci 2006, 47:1477-1485

35. Nguyen SM, Alexejun CN, Levin LA: Amplification of a reactive oxygen species signal in axotomized retinal ganglion cells. Antioxid Redox Signal 2003, 5:629-634

36. Kanamori A, Catrinescu MM, Kanamori N, Mears KA, Beaubien R, Levin LA: Superoxide is an associated signal for apoptosis in axonal injury. Brain 2010, 133:2612-2625

37. Schlieve CR, Tam A, Nilsson BL, Lieven CJ, Raines RT, Levin LA: Synthesis and characterization of a novel class of reducing agents that are highly neuroprotective for retinal ganglion cells. Exp Eye Res 2006, 83:1252-1259

38. Eckshtain M, Zilbermann I, Mahammed A, Saltsman I, Okun Z, Maimon E, Cohen H, Meyerstein D, Gross Z: Superoxide dismutase activity of corrole metal complexes. Dalton Trans 2009, 38: 7879-7882

39. Kanamori A, Catrinescu MM, Mahammed A, Gross Z, Levin LA: Neuroprotection against superoxide anion radical by metallocorroles in cellular and murine models of optic neuropathy. J Neurochem 2010, 114:488-498

40. Gross Z, Galili N: N-substituted corroles: a novel class of chiral ligands. Angew Chem Int Ed Engl 1999, 38:2366-2369

41. Rovira C, Kunc K, Hutter J, Parrinello M: Structural and electronic properties of Co-corrole, Co-corrin, and Co-porphyrin. Inorg Chem 2001, 40:11-17

42. Reig AJ, Conrad KS, Brunold TC: Combined spectroscopic/computational studies of vitamin B12 precursors: geometric and electronic structures of cobinamides. Inorg Chem 2012, 51:2867-2879

43. Thompson AF, Crowe ME, Lieven CJ, Levin LA: Induction of neuronal morphology in the $661 \mathrm{~W}$ cone photoreceptor cell line with staurosporine. PLoS One 2015, 10:e145270

44. Zhao H, Kalivendi S, Zhang H, Joseph J, Nithipatikom K, VasquezVivar J, Kalyanaraman B: Superoxide reacts with hydroethidine but forms a fluorescent product that is distinctly different from ethidium: potential implications in intracellular fluorescence detection of superoxide. Free Radic Biol Med 2003, 34:1359-1368

45. Robinson KM, Janes MS, Pehar M, Monette JS, Ross MF, Hagen TM, Murphy MP, Beckman JS: Selective fluorescent imaging of superoxide in vivo using ethidium-based probes. Proc Natl Acad Sci U S A 2006, 103:15038-15043

46. Forkink M, Willems PH, Koopman WJ, Grefte S: Live-cell assessment of mitochondrial reactive oxygen species using dihydroethidine. Methods Mol Biol 2015, 1264:161-169

47. Mc Guire PJ, Parikh A, Diaz GA: Profiling of oxidative stress in patients with inborn errors of metabolism. Mol Genet Metab 2009, 98:173-180

48. Richard E, Jorge-Finnigan A, Garcia-Villoria J, Merinero B, Desviat LR, Gort L, Briones P, Leal F, Perez-Cerda C, Ribes A, Ugarte M, Perez B; MMACHC Working Group: Genetic and cellular studies of oxidative stress in methylmalonic aciduria (MMA) cobalamin deficiency type $\mathrm{C}$ (cblC) with homocystinuria (MMACHC). Hum Mutat 2009, 30:1558-1566

49. Chester EM, Agamanolis DP, Harris JW, Victor M, Hines JD, Kark JA: Optic atrophy in experimental vitamin B12 deficiency in monkeys. Acta Neurol Scand 1980, 61:9-26

50. Jarrett SG, Lin H, Godley BF, Boulton ME: Mitochondrial DNA damage and its potential role in retinal degeneration. Prog Retin Eye Res 2008, 27:596-607

51. Hamel CP: Cone rod dystrophies. Orphanet J Rare Dis 2007, 2:7

52. Levin LA: Mechanisms of retinal ganglion specific-cell death in Leber hereditary optic neuropathy. Trans Am Ophthalmol Soc 2007, 105:379-391

53. Levin LA: Superoxide generation explains common features of optic neuropathies associated with cecocentral scotomas. J Neuroophthalmol 2015, 35:152-160

54. Lieven CJ, Thurber KA, Levin EJ, Levin LA: Ordering of neuronal apoptosis signaling: a superoxide burst precedes mitochondrial cytochrome $\mathrm{c}$ release in a growth factor deprivation model. Apoptosis 2012, 17:591-599

55. Catrinescu MM, Chan W, Mahammed A, Gross Z, Levin LA: Superoxide signaling and cell death in retinal ganglion cell axotomy: effects of metallocorroles. Exp Eye Res 2012, 97:31-35

56. Scott CJ, Seidler EA, Levin LA: Cell-autonomous generation of mitochondrial superoxide is a signal for cell death in differentiated neuronal precursor cells. Brain Res 2010, 1306:142-148

57. Yuki K, Ozawa Y, Yoshida T, Kurihara T, Hirasawa M, Ozeki N, Shiba D, Noda K, Ishida S, Tsubota K: Retinal ganglion cell loss in superoxide dismutase 1 deficiency. Invest Ophthalmol Vis Sci 2011, 52:4143-4150

58. Zelko IN, Mariani TJ, Folz RJ: Superoxide dismutase multigene family: a comparison of the CuZn-SOD (SOD1), Mn-SOD (SOD2), and EC-SOD (SOD3) gene structures, evolution, and expression. Free Radic Biol Med 2002, 33:337-349

59. Kussmaul L, Hirst J: The mechanism of superoxide production by NADH:ubiquinone oxidoreductase (complex I) from bovine heart mitochondria. Proc Natl Acad Sci U S A 2006, 103:7607-7612

60. Waxman SG: Prerequisites for conduction in demyelinated fibers. Neurology 1978, 28:27-33

61. Carelli V, Ross-Cisneros FN, Sadun AA: Mitochondrial dysfunction as a cause of optic neuropathies. Prog Retin Eye Res 2004, 23:53-89

62. Newman NJ, Biousse V, Newman SA, Bhatti MT, Hamilton SR, Farris BK, Lesser RL, Turbin RE: Progression of visual field defects in Leber hereditary optic neuropathy: experience of the LHON treatment trial. Am J Ophthalmol 2006, 141:1061-1067

63. Kerrison JB, Newman NJ: Clinical spectrum of Leber's hereditary optic neuropathy. Clin Neurosci 1997, 4:295-301

64. Baracca A, Solaini G, Sgarbi G, Lenaz G, Baruzzi A, Schapira AH, Martinuzzi A, Carelli V: Severe impairment of complex I-driven adenosine triphosphate synthesis in leber hereditary optic neuropathy cybrids. Arch Neurol 2005, 62:730-736 
65. Buccellato FR, Miloso M, Braga M, Nicolini G, Morabito A Pravettoni G, Tredici G, Scalabrino G: Myelinolytic lesions in spinal cord of cobalamin-deficient rats are TNF-alpha-mediated. FASEB J 1999, 13:297-304

66. Scalabrino G, Peracchi M: New insights into the pathophysiology of cobalamin deficiency. Trends Mol Med 2006, 12:247-254

67. Veber D, Mutti E, Tacchini L, Gammella E, Tredici G, Scalabrino G: Indirect down-regulation of nuclear NF-kappaB levels by cobalamin in the spinal cord and liver of the rat. J Neurosci Res 2008, 86: $1380-1387$
68. Morgan MJ, Liu ZG: Crosstalk of reactive oxygen species and NFkappaB signaling. Cell Res 2011, 21:103-115

69. Dassanayake RS, Farhath MM, Shelley JT, Basu S, Brasch NE: Kinetic studies on the reaction of cob(II)alamin with hypochlorous acid: evidence for one electron oxidation of the metal center and corrin ring destruction. J Inorg Biochem 2016, 163:81-87

70. Krishnamoorthy RR, Clark AF, Daudt D, Vishwanatha JK, Yorio T: A forensic path to RGC-5 cell line identification: lessons learned. Invest Ophthalmol Vis Sci 2013, 54: $5712-5719$ 